\title{
Registros de erosão e progradação revelados por radar de penetração do solo (GPR) na barreira regressiva pleistocênica do complexo deltaico do Rio Paraíba do Sul (RJ) Erosion and progradational records revealed by ground penetrating radar in the regressive pleistocene barrier in Paraiba do Sul deltaic complex $(R J)$
}

Thaís Baptista da Rocha ${ }^{\text {ab }}$, Guilherme Borges Fernandez ${ }^{\text {ac }}$, Amilson Rodrigues ${ }^{\text {ad }}$

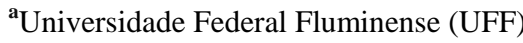

bthaisbaptista@id.uff.br, ${ }^{\mathbf{c}}$ guilhermefernandez@id.uff.br, ${ }^{\mathbf{d}}$ amilsom2@uol.com.br

\begin{abstract}
Resumo
A estratigrafia e a arquitetura deposicional das barreiras regressivas refletem os processos que ocorreram durante a progradação desse sistema, decorrentes do comportamento do nível relativo do mar e do aporte sedimentar, podendo formar extensas planícies costeiras como no caso do Complexo Deltaico do Rio Paraíba do Sul (CDRPS). A utilização do Radar de Penetração do Solo (GPR) tem possibilitado novas discussões acerca dessas feições a partir da identificação de registros de fases de erosão, eventos de alta energia decorrentes de ondas de tempestade; e retrabalhamento por drenagens e pela ação eólica. O objetivo do presente trabalho é caracterizar as radarfácies e as superfícies erosivas da barreira regressiva pleistocênica do CDRPS, a partir da utilização do GPR, considerando as características geomorfológicas da respectiva planície. Foram utilizadas antenas de $200 \mathrm{MHz}$ em modo Common-offset; e de $80 \mathrm{MHz}$ em modo CMP para correção da velocidade da onda em profundidade. Foram identificadas radarfacies que compõe uma sequência regressiva (f1, f2, f3 e f4); radarfácies associadas ao preenchimento da depressão intra-crista(f5); leques de transposição (f7); barras offshore (f3a); além da identificação das superfícies erosivas. Estes últimos refletores representam interrupções na progradação da planície, correspondente a uma fase ou evento erosivo que, inclusive, se expressa nos truncamentos dos alinhamentos das cristas de praia. Nesse sentido, foi possível identificar radarfácies nas barreiras regressivas que extrapolam a arquitetura deposicional como reflexo apenas da progradação, como os refletores que marcam os registros de fases erosivas, bem como os refletores que permitem avaliar os aspectos da dinâmica geomorfológica, no que se refere á gênese e ao retrabalhamento associado à hidrodinâmica das drenagens localizadas entre as depressões das cristas de praia.
\end{abstract}

Palavras-chave: Radar de penetração do solo; arquitetura deposicional; cristas de praia

\begin{abstract}
The stratigraphy and depositional architecture of regressive barriers reflect the progradation process due to sea level behaviour and sediment supply, with the possibility of extensive coastal plain formation, as occurs in the Paraíba do Sul River Deltaic Complex (CDRPS). The use of GPR has enabled further discussion about these features by identifying records of erosion phases, high-energy events and reworking by drainage and wind action. The main of this study is to identify the radarfacies of the Pleistocene regressive barrier in the CDRPS, using GPR, and considering the given geomorphological characteristics of the respective coastal plain. A $200 \mathrm{MHz}$ antenna was used, in Common-offset mode; and an $80 \mathrm{MHz}$, in CMP mode for the depth correction. Sequences of regressive radarfacies were identified (f1, f2, f3 and f4) and other radarfacies associated with the swale infilling (f5), washover fans (7), offshore bars (f3a), and erosional surfaces. These last reflectors represent interruptions in the progradation of the coastal plain, followed by a phase or an erosional event that is express by the truncation of the beach ridge alignment. Thus, it was identifiedthe radarfaciesthat surpass the depositional architecture as the result of progradation, as erosional records and geomorphological dynamics aspects about beach ridges.
\end{abstract}

Key words: Ground penetrating radar; deposicional architecture; beach ridges

\section{Introdução}

As barreiras costeiras são feições deposicionais arenosas, comuns em costas dominadas por ondas, onde estas predominam sob a forçante de maré, representado cerca de $15 \%$ dos totais de linhas de costas do mundo (Roy et al. 1994, Dillenburg \& Hesp 2009, Otvos 2012). Considerando as características morfológicas, estratigráficas e do comportamento da linha de costa, as barreiras costeiras podem ser 
agrupadas em três principais tipologias: regressiva, transgressiva ou agradacional, embora existam outras tipologias mais específicas (Fernandez \& Rocha 2015, Otvos 2012, Dillenburg \& Hesp, 2009, Roy et al.1994, Niedoroda et al. 1985, Kraft \& John 1979).

No caso das barreiras regressivas, estas têm como característica principal a progradação da barreira em direção ao mar, geralmente marcando uma sucessão de cristas de praias (beachridges), dunas frontais (foreduneridges) ou de fases de campos de dunas transgressivos marcados por cristas de precipitação (Hesp et al. 2005). Cada crista marca uma paleolinha de costa e resultam em planícies costeiras bem desenvolvidas, que passam a guardar importantes registros da respectiva evolução quaternária (Tamura 2012).

A progradação pode ocorrer a partir de regressão forçada ou regressão normal, considerando as variações de nível de base e aporte sedimentar. A regressão forçada irá ocorrer com a queda do nível do mar, independente da taxa de aporte sedimentar. Já a regressão normal ocorrerá quando a taxa de aporte sedimentar superar a taxa de criação de espaço de acomodação. Neste caso, a progradação pode ocorrer mesmo sob condições de nível relativo do mar estável ou em elevação (Posamentier et al. 1988, Holz 2012).

Em resposta à progradação, a sequência vertical esperada da base para o topo é as fácies de antepraia, estirâncio, pós-praia e dunas. Esta estratigrafia normalmente pode apresentar camadas intercaladas de areia, silte e argilas, indicativo de ambiente de antepraia inferior; seguida de camadas arenosas que podem apresentar gradativo aumento granulométrico, entre o ambiente de antepraia superior, estirâncio e pós-praia. Podem ser encontradas laminações planoparalelas, de baixo-ângulo e estruturas cruzadas no ambiente de antepraia; e acamamentos com mergulho em direção ao mar nas fácies praiais (Elliot 1978, Kraft \& John 1979).

Apesar da estratigrafia e da arquitetura deposicional das barreiras regressivas serem bem conhecidas na literatura, a utilização de técnicas de subsuperfície contínuas espacialmente e não-invasivas, como o GPR (Radar de Penetração do Solo/Ground Penetrating Radar), têm possibilitado novas discussões acerca dessas feições em um contexto evolutivo. Buynevitch et al. (2009) reconhecem que sequências regressivas podem apresentar evidências de eventos erosivos, como escarpas e leques de transposição excepcionais. Silva et al. (2014), Dillenburg et al. (2014) e Barboza et al. (2014) identificaram truncamentos erosivos por canais e paleocanais de rios que meandraram em barreiras regressivas, e até mesmo interfaces complexas de ambientes fluviais e marinhos em planícies costeiras. Os autores reconhecem a potencialidade do GPR para a identificação dessas evidências através da geometria e continuidade dos registros geofísicos.

No litoral brasileiro, a maioria das barreiras regressivas investigadas são holocênicas, uma vez que estão condicionadas ao comportamento de queda do nível relativo do mar nos últimos 5.500 anos A.P., cujos principais exemplos estão no litoral Sul (Angulo et al. 2006, Lessa et al. 2000, Souza et al. 2012, Dillenburg et al. 2011, Barboza et al. 2009, Barboza et al. 2011). Também já foram investigadas planícies regressivas que, além desse comportamento do nível do mar, possuem seu desenvolvimento associado a importantes contribuições de aporte sedimentar fluvial, como as planícies do rio Paraíba do Sul, do rio São Francisco e do rio Doce (Dominguez 1981, Dominguez et al. 1987, Cohen et al. 2014, Fernandez \& Rocha 2015).

Nesse contexto, o Complexo Deltaico do Rio Paraíba do Sul (CDRPS), localizado no estado do Rio de Janeiro, é um interessante exemplo de interação entre o comportamento do nível do mar e o aporte sedimentar fluvial, que influenciaram a sua história evolutiva durante o Quaternário. Especificamente o setor meridional do CDRPS, apresenta uma planície costeira bem preservada, formada por cristas de praia com idade de aproximadamente 80.000 anos e com características morfoestratigráficas de barreira regressiva (Rocha et al. 2013a). Logo, o objetivo do presente trabalho é caracterizar as radarfácies da barreira regressiva pleistocênica do CDRPS, a partir da utilização de GPR, considerando, ainda, os seus aspectos geomorfológicos. Além disso, espera-se investigar a ocorrência de possíveis interrupções no processo de progradação e registros erosivos, bem como registros de retrabalhamento e gênese em relação às cristas de praias.

\section{2. Área de estudo}

A respectiva área de estudo faz parte do CDRPS que engloba a porção emersa da Bacia de Campos, com uma área equivalente a $2.500 \mathrm{~km}^{2}$. De acordo com Dias (1981), o CDRPS é definido como um conjunto de ambientes sedimentares relacionados às diversas fases de desenvolvimento deltaico do rio Paraíba do Sul, podendo ser dividido em dois eixos principais. $\mathrm{O}$ primeiro, ao sul do cabo de São Tomé, engloba a Lagoa Feia, os sistemas de cristas de praia pleistocênicas e a barreira transgressiva holocênica; e o segundo, ao norte do mesmo cabo, envolve o delta atual do rio Paraíba do Sul, também de idade holocênica (figuras $1 \mathrm{~A}$ e 1B).

Considerando as características geomorfológicas do entorno, a respectiva planície que concentra a área de estudo é bordejada ao Sudoeste pelo domínio suave colinoso, referente ao embasamento Pré-Cambriano; ao Norte, pelos Tabuleiros relacionados aos fragmentos do Grupo Barreiras; e ao Nordeste pela Lagoa Feia e por planícies flúvio-lagunares (figura $1 \mathrm{C}$ ). A maior parte desta planície encontra-se dentro dos limites do Parque Nacional de Jurubatiba, compreendendo aproximadamente 15.000 hectares, sendo constituído por um conjunto de ecossistemas de elevada biodiversidade, englobando lagunas, restingas e brejos. 
Essa planície costeira pleistocênica envolve seis unidades de sistemas de cristas de praia, mapeadas de acordo com os truncamentos identificados nos alinhamentos predominantes. Estas feições se apresentam cortadas por uma pequena rede de drenagem, geralmente conectada a um complexo de lagoas costeiras que são truncadas pela barreira transgressiva que se estende de Macaé ao cabo de São Tomé/RJ (figura 1C).

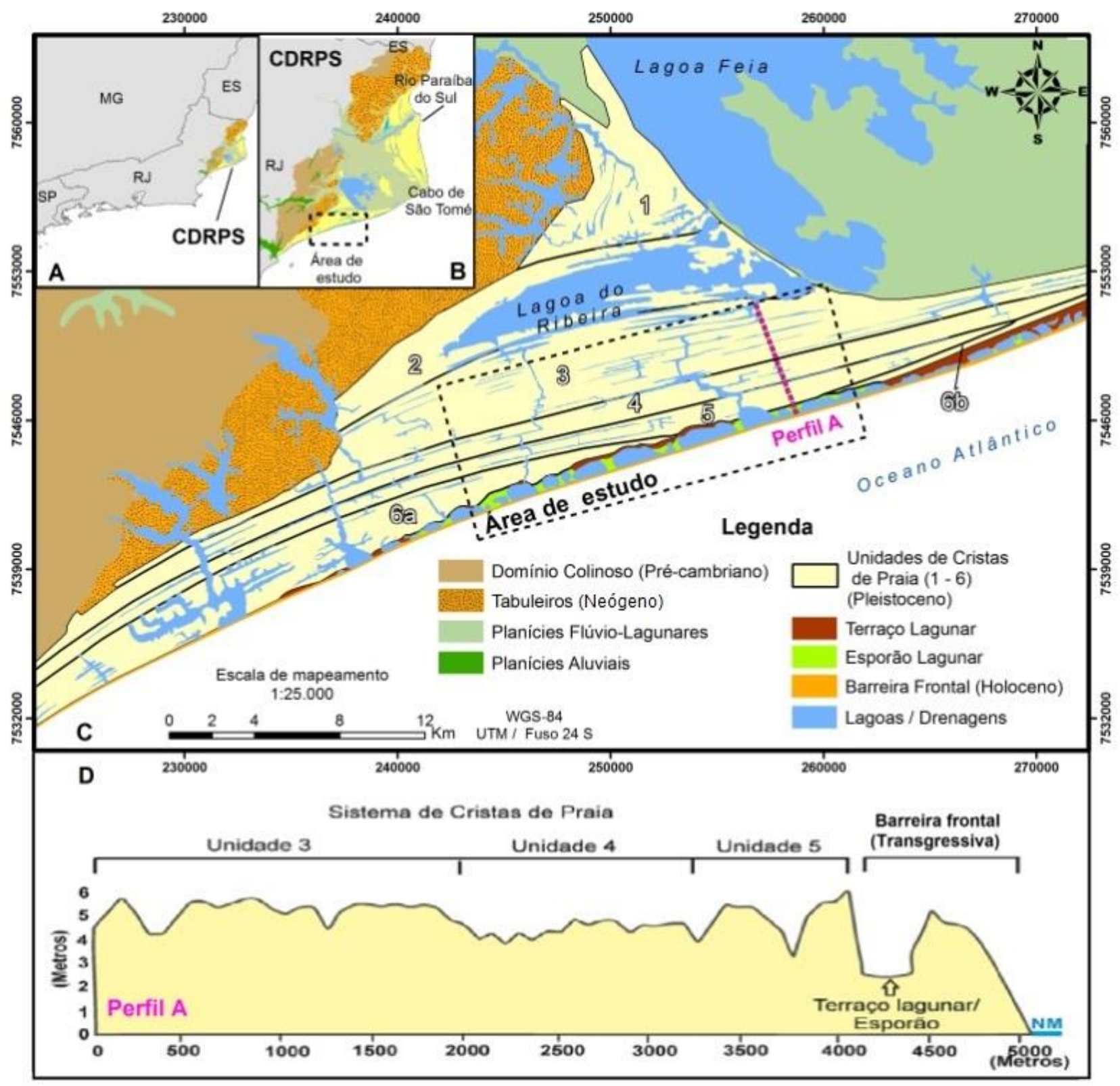

Figura 1 (A)/(B): Localização do Complexo Deltaico do Rio Paraíba do Sul (CDRPS); (C) Mapeamento geomorfológico do setor meridional do CDRPS em escala 1:25.000 (Elaborado por Rocha 2013); (D) Perfil topográfico transversal de parte da planície costeira

O presente trabalho está concentrado nas unidades de sistemas de cristas 3, 4, 5 e 6, que possuem alinhamento NE-SW, larguras entre 100 e $150 \mathrm{~m} \mathrm{e}$ cotas que variam entre 4,5 e 6,0 m, em relação ao nível médio do mar (figura 1). Este setor já era considerado por Silva (1987) como possível registro pleistocênico posterior à transgressão Cananéia, ocorrida há 120.000 anos A.P. Essa idade foi estimada de forma relativa a partir das datações obtidas por Martin et al. (1984) que dataram conchas contidas nas fácies de lamas arenosas das lagoas, posicionadas à frente das cristas de praia e que são truncadas pela barreira transgressiva. Como as idades foram estimadas entre 5.000 e 6.600 A.P., a planície de cristas de praia posicionada no reverso desse sistema foi interpretada como pleistocênica.

As primeiras datações obtidas a partir dos métodos de Luminescência Opticamente Estimulada (LOE) apresentaram idades em torno de 80.000 anos, correspondendo ao Estágio Isotópico Marinho (MIS) 5a. Apesar do número reduzido de alíquotas utilizado para calcular a Dose Equivalente (DE) das amostras, também foram datados por AMS amostras de horizonte B espódico. As idades foram superiores a 43.500 A.P., 
corroborando a idade pleistocênica das cristas de praia (Rocha et al. 2003a, Rocha \& Fernandez 2015).

Com relação aos aspectos oceanográficos da área, esta se caracteriza pela influência de um padrão de micro-maré com amplitude de até $1,3 \mathrm{~m}$, de acordo com as informações da Diretoria de Hidrografia e Navegação (DHN). Dados levantados por Souza (1988) expressam, que ao longo do ano, a maior frequência da direção de incidência de ondas está associada a ventos locais do quadrante NE e E, ocorrendo ainda ondas provenientes dos quadrantes SE e SW; e S, associadas à passagem de sistemas frontais, cuja altura pode ultrapassar os $3 \mathrm{~m}$.

\section{Materiais e métodos}

Considerando a elevada extensão da planície costeira e as dificuldades de acesso, as investigações se concentraram em duas áreas da planície. Em cada uma dessas áreas foram realizadas aquisições de linhas de GPR (modelo SIR-2000, fabricado pela Geophysical Survey Systems, Inc./ GSSI ${ }^{\mathrm{TM}}$ ) em dois transectos principais (figura 2), em modo Common-offset, com uma antena de frequência central de $200 \mathrm{MHz}$ (figura 3). Em relação aos parâmetros de aquisição, a janela de amostragem (Range) variou entre 450 e 400 n/s (nanosegundos) e foram utilizadas 1024 amostras por traço (Amostras/Scan). Simultaneamente às aquisições de GPR, a perfilagem topográfica foi realizada por um sistema DGPS (modelo GTR-G2 da TechGeo), cujas cotas foram estabelecidas na forma ortométrica, que possui como referencial o nível médio do mar. Foram obtidas, aproximadamente, $8 \mathrm{~km}$ de linhas de GPR, porém serão apresentadas as mais representativas (figuras 2 e 3 ).

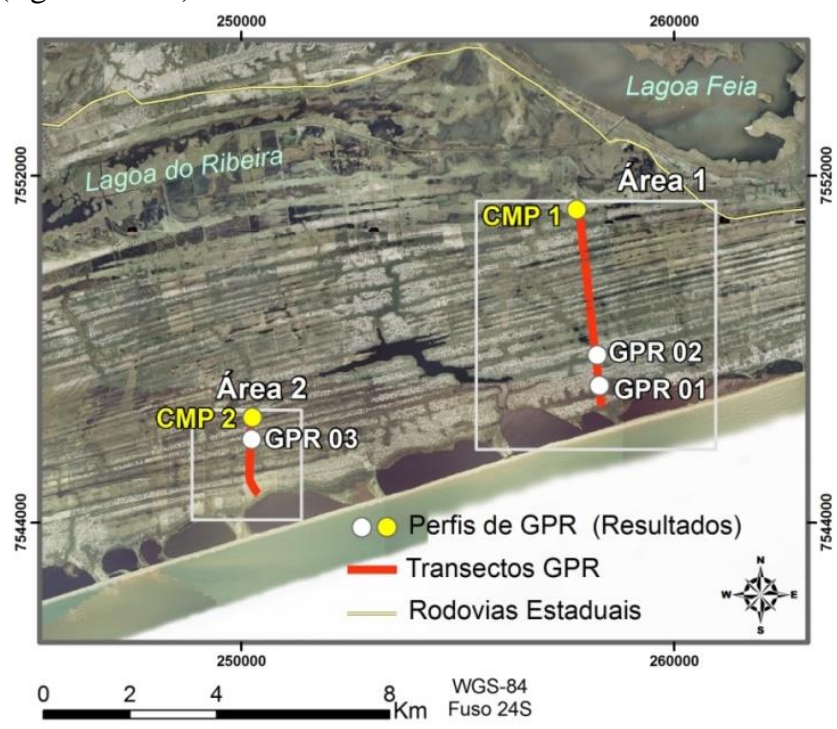

Figura 2: Localização dos perfis de GPR. Notar a sucessão de feixes de cristas de praia compondo a planície costeira.

Buscando a correção do tempo em profundidade das linhas adquiridas, também foram realizados dois perfis em modo Common Mid- Point (CMP), com duas antenas separadas, de frequência central de $80 \mathrm{MHz}$ (figura 2). As duas antenas se distanciaram num igual intervalo de $20 \mathrm{~cm}$, atingindo uma extensão de até 20 $\mathrm{m}$ para ambos os lados. Os dados de GPR foram processados no programa RADANTM 6.6. As etapas de processamento foram divididas em fases relacionadas à topografia, perfis de GPR Common-offset e perfis de CMP. A interpretação dos dados foi obtida a partir da descrição das radarfácies, considerando a morfologia, mergulho, continuidade, terminação e a relação entre os refletores adjacentes, conforme Neal (2004). Também foram identificadas as superfícies de radar, que limitam as camadas deposicionais. A interpretação e a produção das figuras finais foram realizadas no programa CorelDRAW X5.

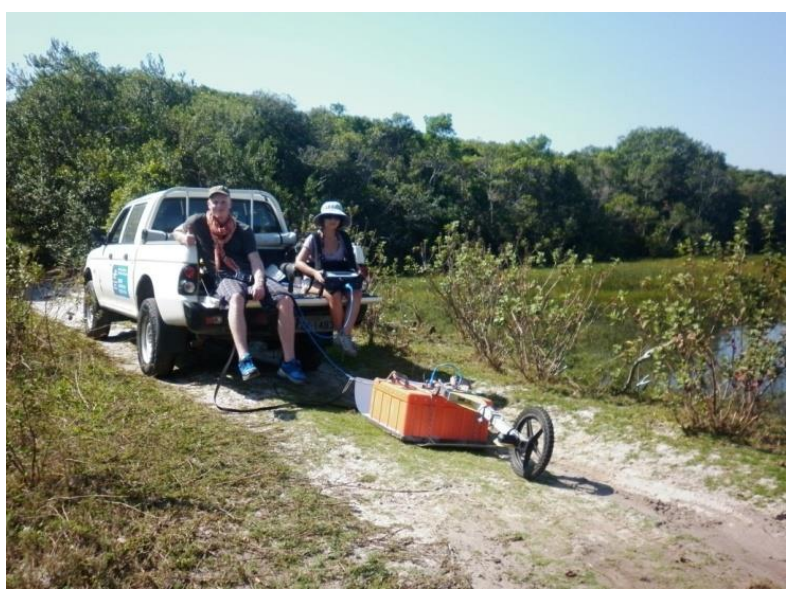

Figura 3: Perfil GPR em modo Common-offset com antena de 200 MHz. Latitude7549076 m; longitude 258765 m (Fuso 24 S).

\section{Resultados e discussões}

\subsection{Descrição das radarfácies e interpretações gerais}

A utilização da antena de $200 \mathrm{MHz}$ permitiu a identificação de unidades referentes a um pacote sedimentar entre 8 e $10 \mathrm{~m}$ de espessura, de acordo com a correção de perfil de velocidade, obtido pelos CMPs. $\mathrm{O}$ diagrama de velocidades do CMP1 variou entre 0,15 até $0,06 \mathrm{~m} / \mathrm{ns}$ e o CMP 2, entre 0,12 até $0,04 \mathrm{~m} / \mathrm{ns}$. Foram identificadas um total de oito radarfácies (figura 4), obtidas a partir da interpretação de três linhas de GPR (01, 02 e 03), descritas a seguir:

\section{a) Radarfácies f1 - Capeamento eólico}

A radarfácies f1 foi observada nas três linhas interpretadas (GPR-01, GPR-02 e GPR-03). Apresenta boa continuidade, geometria de refletores variando de sub-paralelo à curvado, terminação concordante e apresenta-se restrito à superfície do perfil. Esta radarfácies foi interpretada como de capeamento eólico sobre as cristas de praia. Esta unidade apresenta espessura sedimentar entre 1 e $2 \mathrm{~m}$ (figuras 5, 6 e 7).

\section{b) Radarfácies f2 - Pós-praia e estirâncio}

A f2 é a radarfácies predominante nas três linhas (GPR-01, GPR-02 e GPR-03), com espessura estimada em torno de $3 \mathrm{~m}$. Apresenta boa continuidade nos refletores, geometria sub-paralela à inclinada, com 
mergulho em direção ao mar, gradiente entre $8^{\circ}$ e $10^{\circ} \mathrm{e}$ terminação em downlap. Representa respectivamente os ambientes deposicionais de estirâncio e pós-praia (Foreshore). Especificamente na linha GPR-01, as superfícies de radar, que identificam os limites superiores e inferiores da f2, são concordantes em relação á f1 e à f3 (figura 5). Já nas linhas GPR-02 e GPR-03, não foi possível identificar o limite inferior entre a f2 e f3. Nestas linhas também foram identificadas algumas superfícies erosivas, truncando refletores da f2, cuja extensão vertical pode chegar a até $5 \mathrm{~m}$ do pacote deposicional (figuras 6 e 7).

\section{c) Radarfácies f3 - Antepraia superior}

A f3 também foi identificada nas três linhas de GPR, apresentando em média $2 \mathrm{~m}$ de espessura. Caracterizase por refletores pouco contínuos, de geometria ondulada, com padrão côncavo-convexo, com algumas estruturas cruzadas. Esta radarfácies foi interpretada como de antepraia superior (upper shoreface). De acordo com Tamura et al. (2008), este padrão mais complexo está associado à migração de barras na zona submarina. Na linha GPR-01, o limite superior e inferior apresenta-se de maneira concordante, entre 0 $\mathrm{m}$ e $2 \mathrm{~m}$ abaixo do nível médio do mar (figura 5). Nas linhas GPR 02 e 03, o contato superior não foi definido em função do padrão caótico de refletores decorrentes do ambiente de transição entre a f2 e a f3. Já o contato inferior também não foi definido, em função da atenuação do sinal do GPR. Cabe ressaltar que, algumas das superfícies erosivas que truncam os refletores da f2, possuem expressão espacial até à antepraia superior, onde são observadas até a cota de $2 \mathrm{~m}$ abaixo do nível médio do mar (figuras 6 e 7).

\begin{tabular}{|c|c|c|c|c|}
\hline Radarfácie & Refletor & Descrição & Espessura & Interpretação \\
\hline f1 & 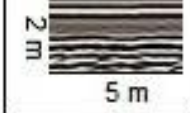 & $\begin{array}{l}\text { Contínuo, sub-parelo à curvado, terminação } \\
\text { concordante, restrito à superfície do perfil }\end{array}$ & $1-2 m$ & Capeamento eólico \\
\hline $\mathrm{f} 2$ & $5 \mathrm{~m}$ & $\begin{array}{l}\text { Contínuo, inclinado, com mergulho em direção } \\
\text { ao continente, com truncamentos erosivos }\end{array}$ & $2,5-3 m$ & Pós-praia e estirâncio \\
\hline f3 & $\frac{\mathrm{in}}{5 \mathrm{~m}}$ & $\begin{array}{l}\text { Refletores ondulados, não-contínuos, com } \\
\text { padrão côncavo/convexo }\end{array}$ & $2 \mathrm{~m}$ & Antepraia superior \\
\hline f3a & $\frac{10 \mathrm{~m}}{3 \text { in }}$ & $\begin{array}{l}\text { Padrão segmentado, configuração sub- } \\
\text { horizontal à ondulada, com mergulho em } \\
\text { direção ao continente; limite superior } \\
\text { discordante. }\end{array}$ & $1,5-2,5 \mathrm{~m}$ & Barras offshore \\
\hline $\mathrm{f} 4$ & $\overrightarrow{5 \mathrm{~m}}$ & $\begin{array}{c}\text { Contínuo, sub-paralelo, terminação em } \\
\text { downlap }\end{array}$ & $1,0-1,5 m$ & Antepraia inferior \\
\hline f5 & $\underset{10 \mathrm{~m}}{\mathrm{~m}}$ & $\begin{array}{l}\text { Parcialmente contínuo, inclinado em direção } \\
\text { ao mar, terminação em downlap }\end{array}$ & $2,0 \mathrm{~m}$ & $\begin{array}{l}\text { Preenchimento da } \\
\text { depressão intra-crista }\end{array}$ \\
\hline f6 & in & Contínuo, sub-horizontal, reflexão atenuada & $1,0 \mathrm{~m}$ & Depósito tecnogênico (aterro) \\
\hline f7 & 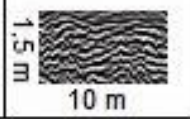 & $\begin{array}{l}\text { Contínuo, com suave mergulho em direção ao } \\
\text { continente, com truncamentos erosivos }\end{array}$ & $1,5 \mathrm{~m}$ & Leques de transposição \\
\hline
\end{tabular}

Figura 4: Quadro de radarfácies contendo as principais características de geometria, espessura e interpretação, que compõe a arquitetura interna da barreira costeira pleistocênica.

\section{d) Radarfácies f3a - Barras offshore}

Essa radarfácies foi identificada na linha GPR-02, apresentando aproximadamente $2 \mathrm{~m}$ de espessura, $80 \mathrm{~m}$ de largura, compondo o ambiente de antepraia superior (figura 6). Caracteriza-se por refletores de padrão segmentado, isto é, de baixa continuidade; configuração sub-horizontal a ondulado, com mergulho em direção ao continente. O limite superior destes refletores é discordante do acamamento das radarfácies f3 (figura 6). A interpretação das radarfácies f3a foi de barras offshore. 


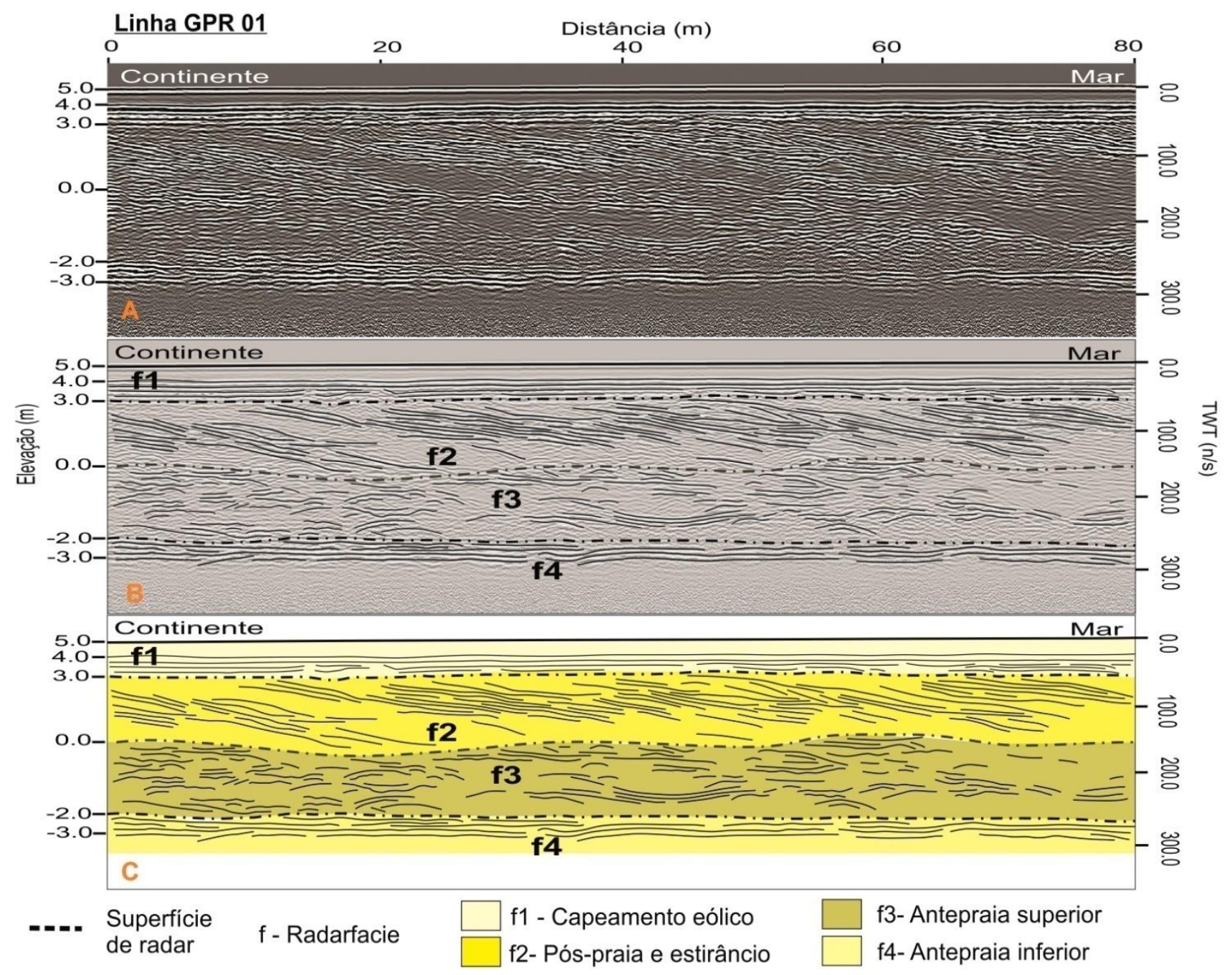

Figura 5: Linha GPR 01, transversal à linha de costa, apresentando radarfácies de progradação. (A) Linha pós-processada; (B) Linha pós-processada, com destaque para a geometria e configuração dos refletores. (C) Linha pós-processada, com destaque para a interpretação das radarfácies.

\section{e) Radarfácies $\mathbf{f 4}$ - Antepraia inferior}

A identificação desta radarfácies ficou limitada à linha GPR-01, cujo limite superior foi concordante em relação à f3. Esta superfície de radar foi identificada à $2 \mathrm{~m}$ abaixo do nível médio do mar e a espessura sedimentar estimada em aproximadamente $1,5 \mathrm{~m}$. Ela é caracterizada por refletores contínuos, com geometria sub-paralela à curvada com baixo gradiente, terminação em downlap (figura 5). Esta radarfácies foi interpretada como de ambiente de antepraia inferior. De acordo com Tamura (2008), não há um critério bem estabelecido para a distinção entre antepraia superior e inferior, mas ressalta que este último tende a apresentar uma deposição com acamamentos mais suaves, em função do decréscimo energético do ambiente.

\section{f) Radarfácies f5 - Preenchimento da depressão intra-cristas}

Essa radarfácies foi identificada na linha GPR-03, na área fisiográfica da depressão entre as cristas de praia (figura 7). Apresenta média continuidade e geometria inclinada com mergulho na direção do mar $e$ terminação em downlap. A f5 se diferencia da $\mathrm{f} 2 \mathrm{em}$ função do sinal mais atenuado, que pode indicar diferenças na composição sedimentar, do contato com uma superfície erosiva côncava que trunca os refletores f2, à $0,5 \mathrm{~m}$ acima do nível médio do mar e do ângulo de mergulho dos refletores, em torno de $4^{\circ}$. Nesse sentido, essa radarfácies apresenta uma geometria de preenchimento, provavelmente decorrente do retrabalhamento das bordas das cristas de praia, a partir da ação hidrodinâmica interna da drenagem inserida na depressão. 


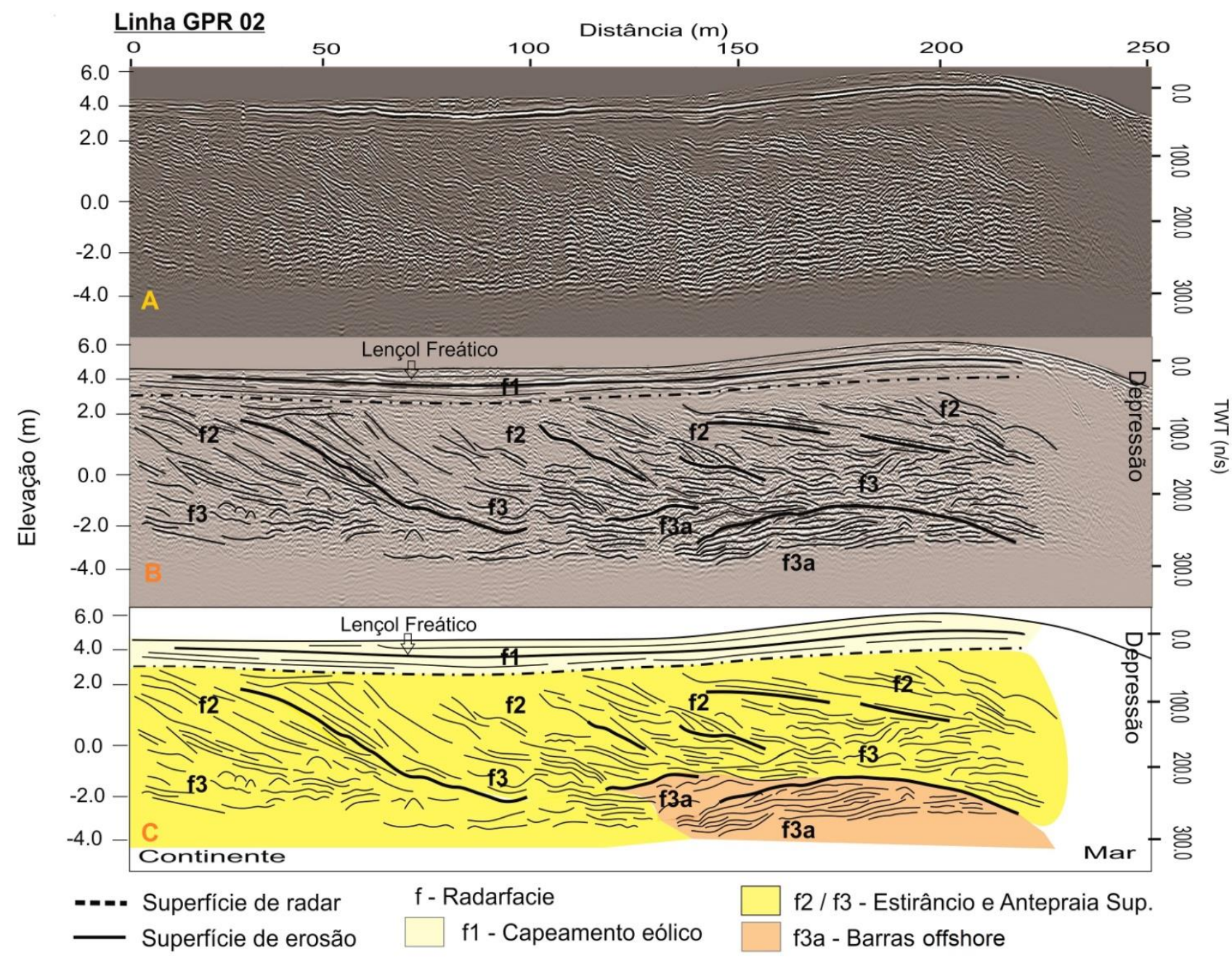

Figura 6: Linha GPR 02, transversal à linha de costa, apresentando superfícies erosivas. (A) Linha pós-processada; (B) Linha pós-processada, com destaque para a geometria e configuração dos refletores. (C) Linha pós-processada, com destaque para a interpretação das radarfácies.

\section{g) Radarfácies f6 - Depósito tecnogênico}

Esta radarfácies aparece restrita à linha GPR-07, com ocorrência limitada à depressão intra-cristas (figura 7). Apresenta característica sub-horizontal e reflexão atenuada, sendo interpretado como depósito tecnogênico. Refere-se a uma camada de cerca de $1 \mathrm{~m}$ de aterro, com o intuito de tornar possível a passagem contínua na estrada que dá acesso a algumas fazendas e povoados. Inclusive, foi isto que possibilitou a obtenção da linha de GPR-03, que cobre cristas e depressões. Cabe ressaltar que nem sobre todas as depressões são depositados material de aterros, exceto onde as drenagens têm dimensões mais expressivas e que dificultam os acessos.

\section{h) Radarfácies f7 - Leques de transposição}

Esses refletores foram identificados na linha GPR03, próximo ao topo da barreira e às superfícies erosivas. Estas apresentam limite superior concordante com as radarfácies f1 e limitadas na parte inferior pela unidade f2, que aparece truncada à cerca de $2,0 \mathrm{~m}$ de profundidade. Os refletores f7 tem configuração subhorizontal a inclinado, com suave mergulho em direção ao continente. Este grupo de radarfácies foi interpretado como leques de transposição. Durante eventos de tempestade, as ondas erodem a berma e a face praial, e quando ultrapassam o topo da barreira, levam sedimentos para o reverso do sistema sob a forma de leques de transposição. 


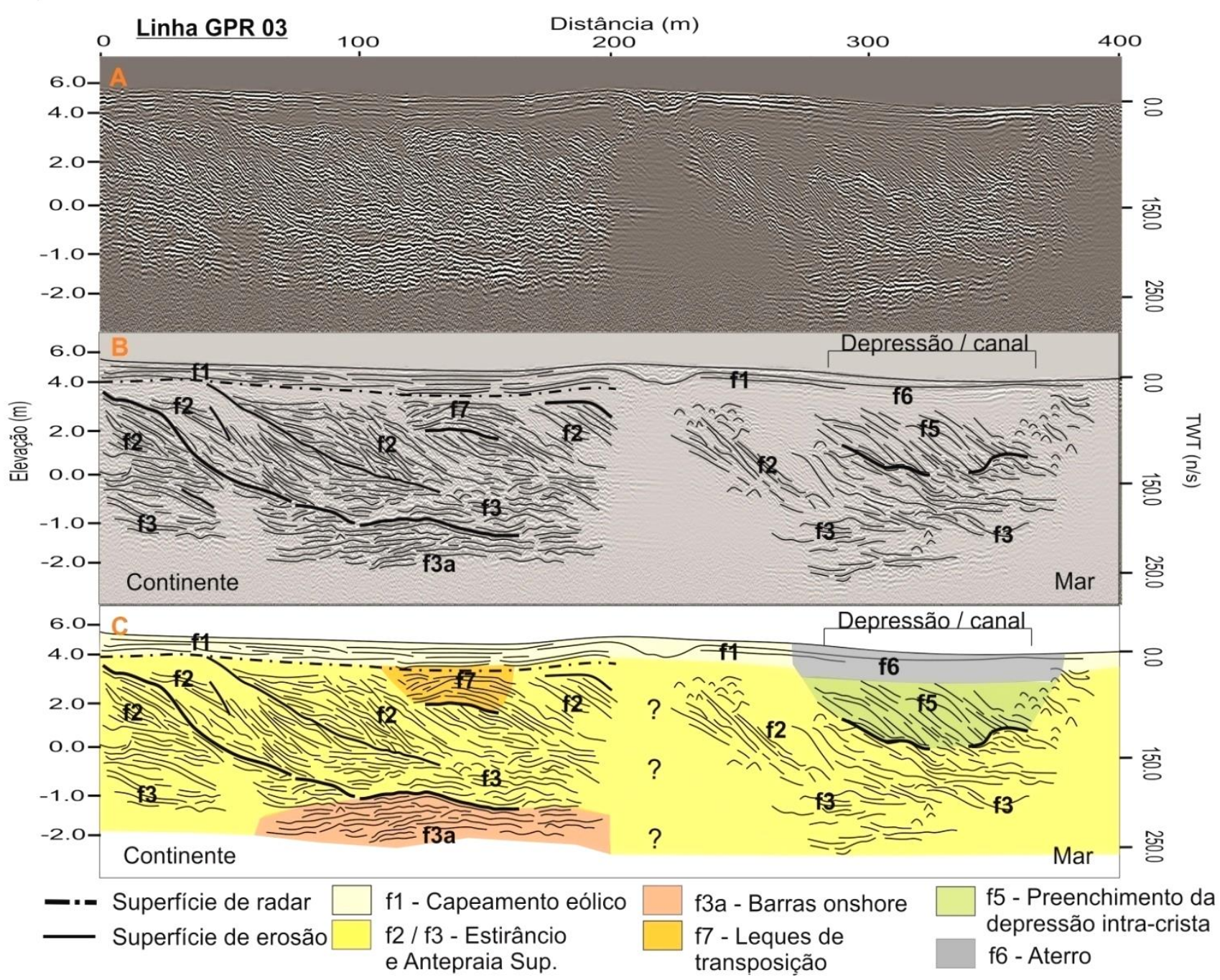

Figura 7: Linha GPR 03, transversal à linha de costa, apresentando superfícies de erosão e de retrabalhamento das cristas. (A) Linha pós-processada; (B) Linha pós-processada, com destaque para a geometria dos refletores. (C) Linha pós-processada, com destaque para a interpretação das radarfácies.

\subsection{Discussões sobre as radarfácies que compõe a arquitetura interna da barreira regressiva}

Algumas das radarfácies interpretadas na barreira regressiva devem ser discutidas no contexto geomorfológico, representada pela planície costeira formada por cristas de praia. Estas são feições associadas à construção pela ação das ondas ou pela ação eólica, de acordo com Otvos (2000) e Tamura (2012). Porém, Hesp et al. (2005) define nomenclaturas diferentes segundo a origem da feição, restringindo o termo "cristas de praia" apenas para cristas construídas pela ação das ondas e "cordões de dunas frontais" para cristas cuja gênese está associada à ação eólica.

Na planície costeira meridional de Santa Catarina e na planície próximo ao Rio Grande, no Rio Grande do Sul, Silva et al. (2010) e Barboza et al. (2011) caracterizaram as sequências de cristas como "cordões de dunas frontais" (Foreduneridges). Em ambos os trabalhos, a radarfácies que compõe os refletores eólicos possui uma geometria mais próxima ao um padrão côncavo-convexo e um pacote sedimentar mais espesso, com aproximadamente 4 m. Já Caldas (2006), Rodriguez \& Meyer (2006), Costas \& FitzGerald (2011) e Billy et al. (2014) identificaram a radarfácies eólica com características semelhantes à f1, identificada no presente trabalho, com característica sub-paralela, terminação concordante, espessura que tende a não ultrapassar $2 \mathrm{~m}$ e que cobre os refletores praiais (f2). Nestes trabalhos, a terminologia mais usual utilizada é a de "cristas de praia" (beachridge).

No presente trabalho, entende-se que a radarfácies f1 não define a forma das cristas, apenas cobre a radarfácies praial (f2) com sedimentos que foram transportados pela ação do vento e que, portanto, o termo "crista de praia" parece ser o mais coerente a ser utilizado. Segundo Rocha et al. (2013a), nas sondagens realizadas na mesma planície, as amostras nas unidades praial e eólica obtidas para análise granulométrica mostraram diferenças apenas em relação ao grau de seleção mais homogêneo, para o caso dos sedimentos eólicos que cobrem as cristas de praia. Não foi identificado diferenças de assimetria e de tamanho do grão, cuja classificação predominante é de areia média. De acordo com Otvos (2000), a ausência de um 
contraste evidente na análise sedimentar de amostras praias e eólicas é característico de pouca atividade eólica atuando na crista de praia. Isso corrobora as características geomorfológicas da planície uma vez que não ocorre a presença de feições eólicas que se destacam, como cortes eólicos (blowouts), rastros de migração, cristas de precipitação ou dunas parabólicas.

Considerando os recentes trabalhos sobre a arquitetura interna das cristas de praia que são investigadas a partir de GPR, a presença de refletores com geometria inclinada e mergulho em direção ao mar, semelhante a radarfácies f2 do presente trabalho, é considerada predominante em termos de ocorrência (Engel \& Roberts, 2005, Rodriguez \& Meyer 2006, Tamura et al. 2008, Billy et al. 2014). Esta arquitetura é relacionada ao mecanismo de gênese de crista de praia associada à construção de bermas, devido à incorporação de sedimentos que são transportados pela ação de ondas de tempo bom (Komar 1998). Ainda assim, é possível ocorrer outras características na arquitetura interna, como a presença de refletores que migram em direção ao continente que podem caracterizar leques de transposição (f7) compondo a crista de praia, ainda que ela seja considerada uma feição associada a um contexto de progradação.

A ocorrência destes depósitos em cristas de praia não é muito comum, ainda assim, Engels \& Roberts (2005) identificaram depósitos de leques compondo a arquitetura sedimentar de uma planície de cristas de praia de composição arenosa e cascalhosa, no Canadá. Os autores associaram a ocorrência desses depósitos a eventos de tempestade e ressaltam que a espessura sedimentar normalmente é limitada e nem sempre pode ser identificado em registros geofísicos. Já Nott et al. (2013) consideraram os leques de transposição como depósito intrínseco à construção das cristas de praia localizada numa planície da Austrália, que é submetida a ocorrência de furacões. Esta abordagem está associada ao modelo de gênese de cristas de praia que se formam com o transporte de sedimentos por ondas de tempestade (Psuty 1965). No presente trabalho, as características da radarfácies $\mathrm{f} 7$, com limite inferior truncando refletores praias (f2), mergulho em direção ao continente e próximo às superfícies erosivas, reiteram a interpretação de leques de transposição. Especificamente na área de estudo, esta ocorrência não pode ser associado com um mecanismo de gênese por ondas de tempestade, uma vez que a ocorrência é bem restrita. Neste caso, a presença dessa radarfácies corrobora apenas a ocorrência de eventos de tempestade, que provavelmente interromperam o processo de progradação da planície, complexificando a arquitetura interna.

Segundo Otvos (2000), dentre os sub-ambientes que se destacam na morfologia de crista de praia está a depressão intra-crista (swale). Esta é caracterizada por ser topograficamente mais baixa que a crista praial, alongada e relativamente estreita, que pode ser preenchida por drenagens, lagoas ou brejos. Recentemente, os registros geofísicos obtidos por GPR têm possibilitado à identificação de refletores característicos desse ambiente. Engels \& Roberts (2005) e Frueggard et al. (2015) interpretaram refletores côncavos à sub-paralelos, com espessura de até $3 \mathrm{~m}$ como depósitos de depressão intra-crista. As aquisições foram realizadas com antena de $100 \mathrm{MHz}$, resultando em refletores pouco detalhados, devido à maior profundidade de penetração do sinal de GPR. Contudo, em ambos os trabalhos a interpretação contou com auxílio de informações de sondagens, cujos depósitos eram compostos por silte, areia e matéria orgânica e, portanto, diferente da composição sedimentar da crista.

No presente trabalho, a radarfácies f5 também foi interpretada como depósitos de preenchimento na depressão intra-cristas, apesar das características dos refletores serem diferentes dos trabalhos citados anteriormente, uma vez que as linhas de GPR foram realizadas no sentido longitudinal à costa. A ocorrência de refletores inclinados, com mergulho em direção ao mar, mas com gradiente mais suave que os refletores praiais (f2), possivelmente podem estar associados ao preenchimento da depressão, devido ao desenvolvimento de cúspides, conforme é possível observar na figura 8. Essas feições podem se desenvolver a partir do retrabalhamento das bordas arenosas das cristas de praia, associada à ação hidrodinâmica interna do corpo d'água que drena na depressão. Este, inclusive, pode ter gerado a superfície erosiva côncava que trunca os refletores da f2 (figura 7). Ainda que em escala espacial menor, processo e refletores semelhantes foram observados nos esporões lagunares que segmentam as lagoas truncadas pela barreira transgressiva holocênica da mesma planície. Esses esporões e cúspides se desenvolvem a partir do retrabalhamento da borda das cristas de praia, na margem interna das lagoas (Rocha et al. 2013b).

Outras hipóteses para a interpretação dessa radarfácies remetem a deposição associada a inlets ou blowouts. No caso deste último, o preenchimento poderia estar relacionado à ação eólica. Porém, na planície investigada esse processo não é expressivo, bem como não há evidências de formas eólicas conforme já discutido anteriormente. No caso da hipótese do inlet, considerando que a área é caracterizada por um contexto de dinâmica costeira dominada pela ação das ondas, uma vez que a amplitude de maré é de apenas 1,3 m (DHN), seria pouco provável o preenchimento de um inlet com fácies exclusivamente com mergulho em direção ao mar, cuja orientação da linha de GPR é transversal à costa. Fitzgerad et al. (2000) e Maio et al. (2016) identificaram radarfácies de paleoinlets em áreas de micro e meso-maré, respectivamente, e verificaram padrões de preenchimento relacionados ao transporte sedimentar em direção ao continente, por ação das ondas e fluxos de enchente, e ao transporte longitudinal. No caso da área investigada, não foi possível realizar a aquisição da linha de GPR na orientação longitudinal à costa, considerada mais 
adequada à interpretação de inlets, uma vez que a radarfácies f5 encontra-se na depressão intra-crista que está preenchido por um corpo d'água. Além disso, informações sedimentológicas obtidas por sondagens também poderiam auxiliar a interpretação menos questionável dessa radarfácies.

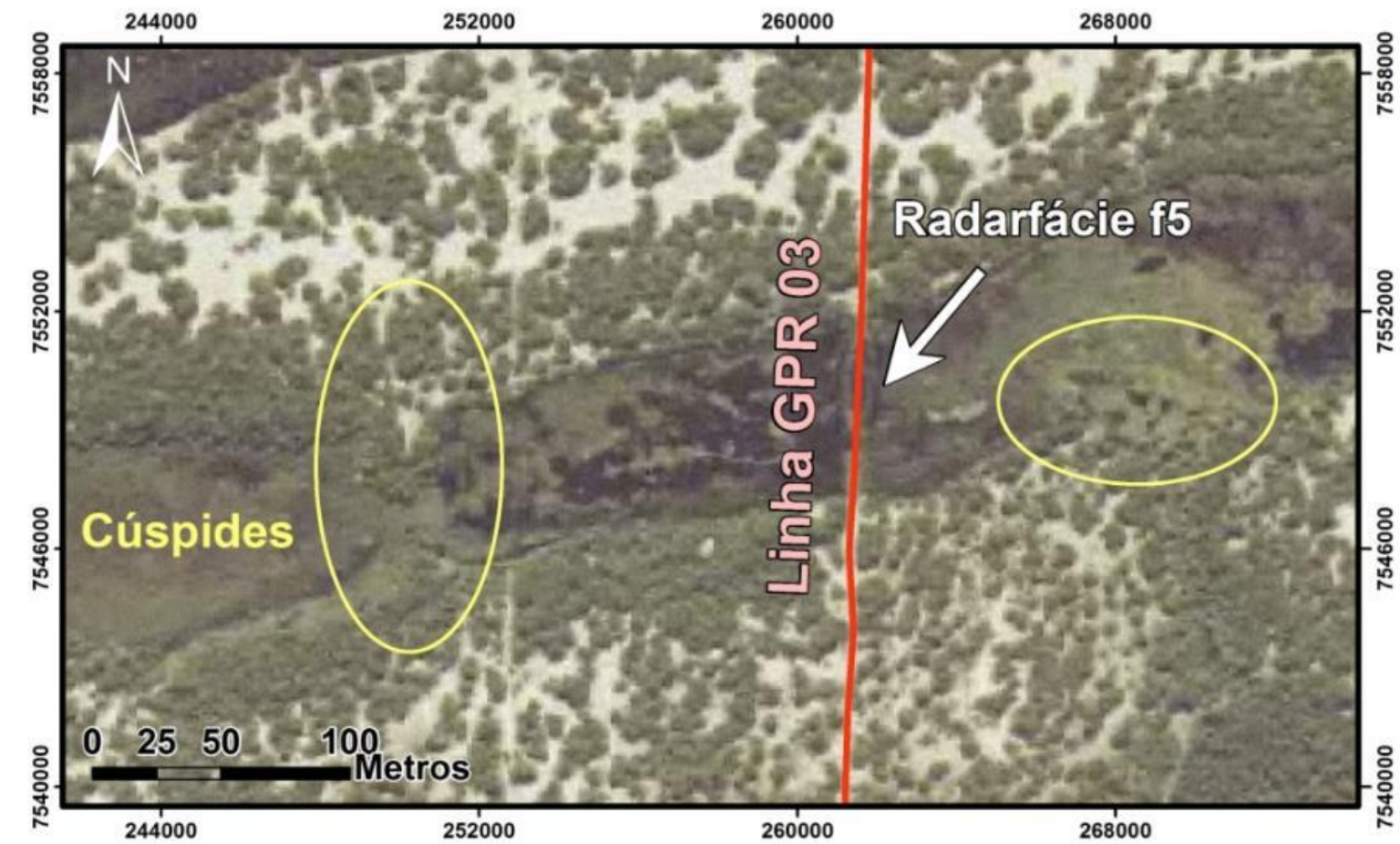

Figura 8: Localização da radarfácies f5 sobre a drenagem na depressão entre cristas. Destaque para o desenvolvimento de cúspides.

\subsection{Discussões sobre a progradação da barreira regressiva}

No transecto onde ocorreram as aquisições das linhas de GPR, cortando transversalmente a planície, as radarfácies f1, f2, f3 e f4 foram as predominantes identificadas na planície. Estas compõema sequência regressiva esperada para barreira costeira, geomorfologicamente representada pela planície de cristas de praia, onde os sedimentos praiais migram sobre o ambiente de antepraia, refletindo em um sistema deposicional em progradação (Kraft \& John 1979, Niedorada et al. 1985, Holz 2012). Como os dados apresentados são restritos em termos espaçotemporais e as cristas de praia possuem idade pleistocênica, referente ao Estágio Isotópico Marinho MIS 5a ( 80.000 anos) (Rocha et al. 2013a, Rocha \& Fernandez 2015), não é possível associar essa progradação a uma queda do nível relativo do mar, isto é, a uma regressão forçada. Curvas do nível relativo do mar que extrapolam o holoceno são consideradas raras em função da dificuldade de preservação dos registros, o que torna difícil a correlação da progradação com esse fator condicionante.

O que se pode inferir é que o aporte sedimentar no local foi maior que a taxa de geração de espaço de acomodação gerando, portanto, a progradação do sistema deposicional. Esse aporte sedimentar pode estar relacionado a uma antiga fase de sedimentação deltaica, possivelmente associada ao antigo curso do rio Paraíba do Sul, cuja foz seria em direção ao Cabo de São Tomé (figura 1B). Este antigo curso do rio éfrequentemente citado em trabalhos referentes à evolução da área do CDRPS, como Lamego (1955), Silva (1987), Bastos (1997), Almeida (1997), Tomaz (2005), Dias \& Kjevre (2009), Rocha et al. (2013a). Ainda assim, há a necessidade de maiores investigações sobre essas alterações no baixo-curso do rio Paraíba do Sul e na plataforma continental adjacente.

Nesse sentido, considerando o delta atual como um análogo à planície pleistocênica investigada no presente trabalho, as radarfácies que compõe a sequência regressiva, representadas pelas f1, f2, f3 e f4, são semelhantes em termos de morfologia e espessura sedimentar à topobatimetria do prisma praial do delta atual do rio Paraíba do Sul (figura 9), conforme já discutido por Rocha et al. (2013a). As radarfácies também são semelhantes às mesmas identificadas em Gargaú, distrito localizado na área do delta atual, apesar da aquisição ter sido realizada com antena de $400 \mathrm{MHz}$, alcançando menor penetração, conforme apresentaram Fernandez \& Rocha (2015). 


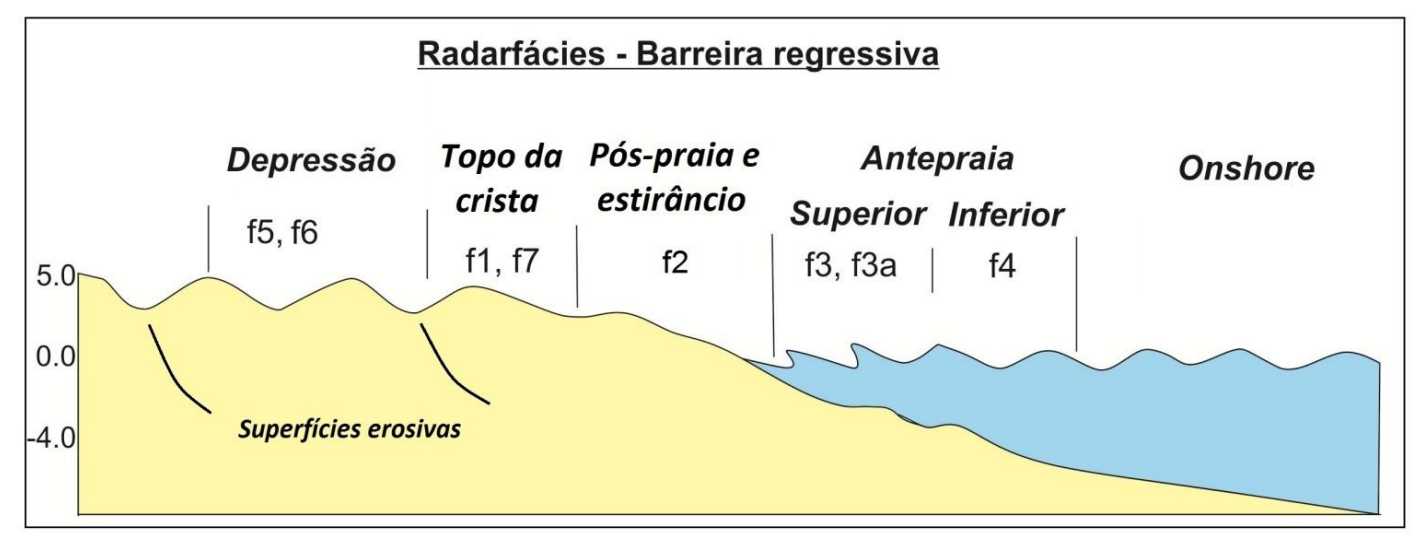

Figura 9: Distribuição das radarfácies e correlação com os subambientes de um perfil praial e cristas de praia. A arquitetura interna reflete a progradação da f2 (praial) sobre a f3 e a f4 (antepraia), além dos registros de eventos ou fases erosivas marcados pelas superfícies erosivas e as radarfácies f7 e f3a. As radarfácies f5 e f1 indicam o retrabalhamento das cristas de praia, posterior à sua gênese.

\subsection{Discussões sobre os registros erosivos na barreira regressiva}

A presença das superfícies erosivas nas linhas de GPR 02 e 03 apresentaram correlação espacial com os truncamentos entre as unidades 4 e 5 das cristas de praia mapeadas em superfície, e também correlação lateral, conforme mostra a figura 10. Essa interrupção do padrão de progradação, provavelmente pode estar associada a eventos de alta energia, como impactos de tempestade, uma vez que a presença das radarfácies f3a e f7 pressupõe relação com estes tipos de evento (figura 9).

Especificamente a radarfácies f3a, interpretada como barras offshore, seriam análogas às barras submarinas que se formam após a passagem de ondas de tempestade. Nestes períodos, grande parte do material erodido do perfil emerso da praia tende a ser transportada para a antepraia, podendo formar as barras. Posteriormente, estas podem retornar para o perfil emerso. Em praias submetidas à uma morfodinâmica intermediária e a uma ação efetiva de ondas de tempestade essa dinâmica pode ser recorrente, conforme já documentaram Muehe et al. (2001). Os autores mapearam uma barra de aproximadamente 100 $\mathrm{m}$ de largura que se formou na antepraia após uma forte ressaca em 2001, na praia da Massambaba, no litoral fluminense. Contudo, refletores com estas características são pouco comuns na literatura, o que dificulta a sua interpretação.

Também no delta atual do rio Paraíba do Sul, registros de subsuperfície relacionados às fases erosivas também foram identificados sob um expressivo truncamento entre os alinhamentos das cristas de praia, no distrito de Atafona, também no delta atual. Nas figuras 11A e 11B, é possível observar superfícies erosivas expressivas e radarfácies semelhantes à $\mathrm{f} 3 \mathrm{a}$, interpretadas como barras offshore (Rocha \& Fernandez em prep.). Apesar de o delta atual ter sua gênese relacionada à progradação decorrente da queda do nível relativo do mar nos últimos 5.500 anos A.P. e ao aporte sedimentar do rio Paraíba do Sul, os truncamentos existentes na respectiva planície são considerados registros em superfície de fases de erosão, conforme apontaram Dias (1981), Martin et al. (1984), Bastos (1997), Tomaz (2005). Este processo erosivo tem sido monitorado nos últimos anos em Atafona (figura 11C) por Santos (2006), Rocha (2009) e Rocha et al. (2013).

\section{Considerações Finais}

As radarfácies f1, f2, f3 e f4 caracterizam o modelo clássico de arquitetura deposicional de barreira regressiva, que reflete o processo de progradação, onde o prisma praial avança sobre a antepraia. Este processo esteve associado a um contexto de expressivo aporte sedimentar, possivelmente associado à contribuição fluvial do antigo curso do rio Paraíba do Sul durante o Pleistoceno. Contudo, a forma contínua de aquisição de GPR com antena de $200 \mathrm{MHz}$, aliado a uma detalhada interpretação de linhas de GPR e a um mapeamento em planta da geomorfologia em escala de detalhe, auxiliaram a interpretação de radarfácies que extrapolam a arquitetura deposicional como reflexo apenas da progradação. Nesse sentido foi possível identificar refletores que marcam registros de fases erosivas, bem como refletores que permitem avaliar aspectos da dinâmica geomorfológica, no que se refere á gênese e ao retrabalhamento das cristas de praia.

As características da radarfácies f1 sustentam a denominação geomorfológica desta barreira como crista de praia (beachridge) e não cordão de dunas frontais (foreduneridge). A geometria da radarfácies $\mathrm{f} 2$ está relacionada à gênese das cristas de praia, associada àincorporação de bermas que são construídas pela ação de ondas de tempo bom; os refletores que preenchem a depressão intra-crista (f5) aparecem possivelmente relacionadas ao retrabalhamento das cristas pela hidrodinâmica dos corpos d'água que drenam nessas áreas mais deprimidas; e às superfícies erosivas, juntamente com as radarfácies de leques de transposição (f7) e de barras offshore (f3a), aparecem provavelmente relacionadas a eventos de alta energia. Nesse sentido, estes últimos refletores representam interrupções na progradação da planície, seguido de uma fase ou evento erosivo que, inclusive, se expressa nos truncamentos dos alinhamentos das cristas de praia. Apesar das limitações decorrentes da ausência de 
análise sedimentar para cada radarfácies que poderia ser obtida através de sondagens, a caracterização dessa arquitetura interna através da interpretação das

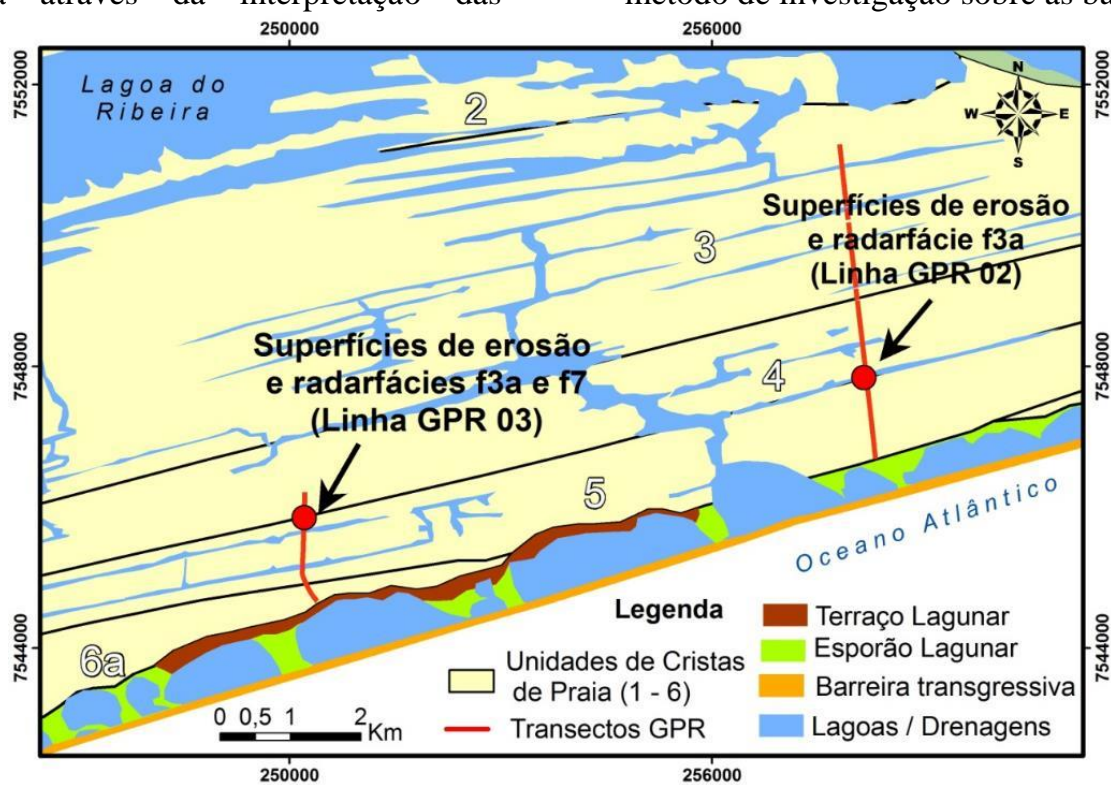

Figura 10: Localização das superfícies erosivas e radarfácies f3a e f7 nas linhas GPR 02 e 03, sob os truncamentos das cristas de praia, entre as unidades 4 e 5 .

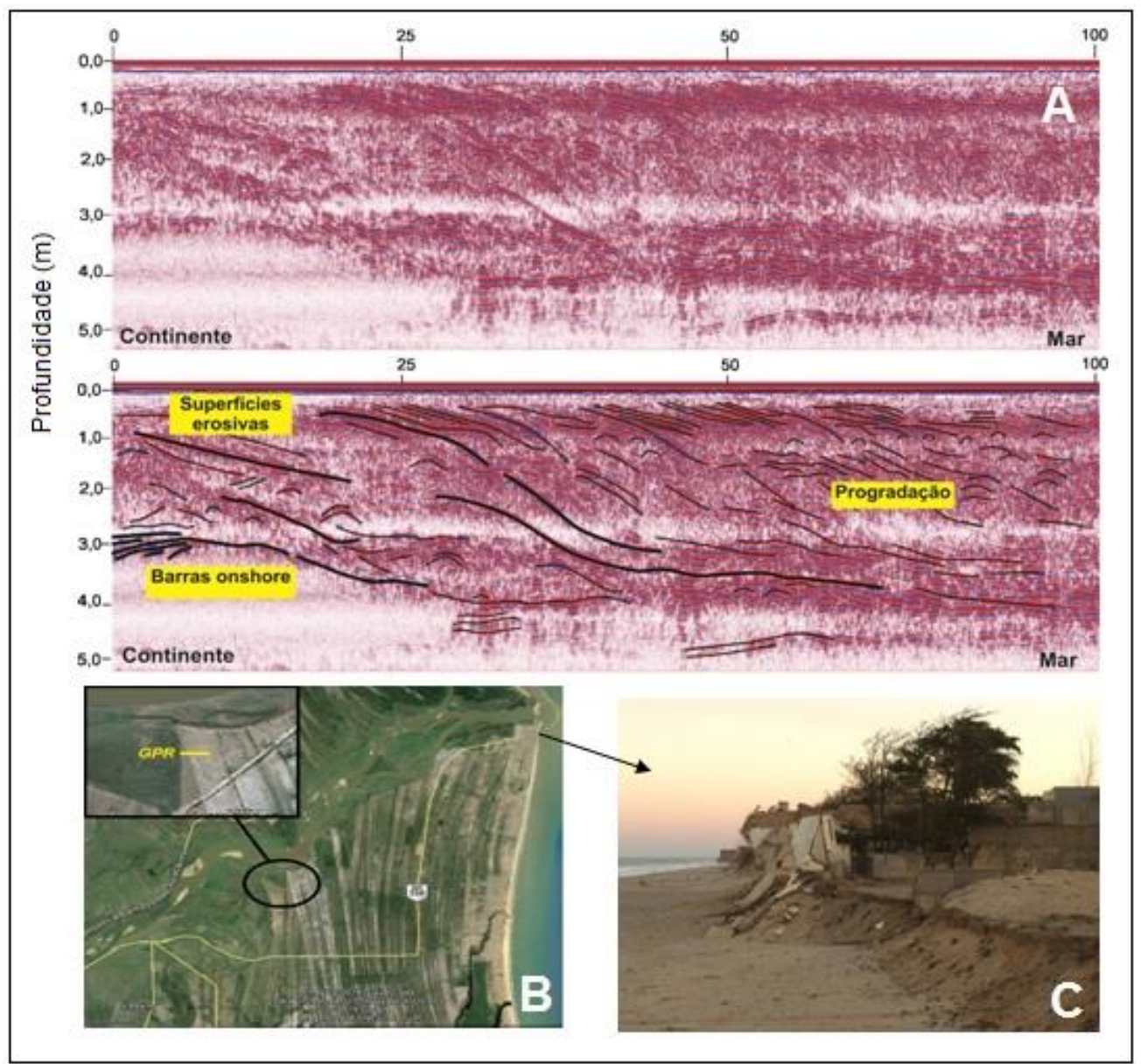

Figura 11 (A e B): Linha de GPR, com antena de $400 \mathrm{MHz}$, realizado num truncamento de cristas de praia do delta atual do rio Paraíba do Sul (Rocha \& Fernandez em prep). Coordenadas: $282342 \mathrm{~m} \mathrm{E} \mathrm{/} 7600382 \mathrm{~m} \mathrm{~S}$ - Fuso 24S (C): Processo de erosão costeira atual, localizado no distrito de Atafona, próxima à foz do rio Paraíba do Sul (Foto de Agosto de 2015). Coordenadas $291536 \mathrm{~m} \mathrm{E} / 7607139 \mathrm{~m} \mathrm{~S}$ - Fuso 24S. 


\section{Agradecimentos}

Aos órgãos de financiamento à pesquisa FAPERJ e CAPES. Ao Laboratório de Geografia Física (LAGEF) da Universidade Federal Fluminense. Ao professor Eduardo Guimarães Barbosa (UFRGS) pelas conversas e orientações sobre a utilização do GPR em barreiras costeiras. Aos avaliadores do artigo pelos importantes questionamentos e sugestões.

\section{Referências bibliográficas}

Almeida M.S. 1997. Evolução geológica da Lagoa de Carapebus Macaé - RJ. Dissertação de Mestrado. Programa de PósGraduação em Geologia e Geofísica Marinha - Instituto Geociências. Universidade Federal Fluminense, Niterói. 118 p.

Angulo R.J., Lessa G.C., Souza M.C. 2006. A critical review of midto late-Holocenesea-level fluctuations on the eastern Brazilian coastline. Quaternary Science Reviews, 25: 486-506.

Barboza E.G., Dillenburg S.R., Rosa M.L.C.C., Tomazelli L.J., Hesp P.A.2009. Ground-penetrating radar profiles of two Holocene regressive barriers in southern Brazil. Journal of Coastal Research, SI 56: 579-583.

Barboza E.G., Rosa M.L.C.C., Hesp P.A., Dillenburg S.R., Tomazelli L.J., Ayup-Zouain R.N. 2011. Evolution of the Holocene Coastal Barrier of Pelotas Basin (Southern Brazil) - a new approach with GPR data. JournalofCoastalResearch, SI 64: 646-650.

Barboza E.G., Rosa M.L.C.C., Dillenburg S.R., Silva A.B., Tomazelli L.J. 2014. Stratigraphic analysis applied on the recognition on the interface between marine and fluvial depositional systems. Journal of Coastal Research, SI 70: 687692.

Bastos A.C. 1997. Análise morfodinâmica e caracterização dos processos erosivos ao longo do litoral norte fluminense, entre Cabiúnas e Atafona.Dissertação de Mestrado. Pós-Graduação em Geologia e Geofísica Marinha, Instituto de Geociências, Universidade Federal Fluminense, 133p.

Billy J., Robin N., Hein C.J., Certain R., Fitzgerald D.M. 2014. Internal architecture of mixed sand-and-gravel beach ridges:Miquelon-Langlade Barrier, NW Atlantic. Marine Geology 357: 53-71.

Buynevich I.V. 2006. Coastal Environmental Changes Revealed in Geophysical Images of Nantucket Island, Massachusetts, U.S.A. Environmental \& Engineering Geoscience, 3: 227-234.

Buynevich I.V., Jol H.M., Fitzgerald D.M. 2009. Coastal Environments. In: JOL, H.M. (Eds) Ground Penetrating Radar: theory and applications. Elsevier Science, 299-322p.

Caldas L.H.O., Oliveira J.G., Medeiro W.E., Karl Stattegger K., Vital H. 2006. Geometry and evolution of Holocene transgressive and regressive barriers on the semi-arid coast of NE Brazil. Geo-Marine Letter, 26: 249-263.

Cohen M.C.L., França M.C., Rossetti D.F., Pessenda L.C.R., Giannini P.C.F., Lorente F.L., Buso Jr A.A. 2014. Landscape evolution during the late Quaternary at the Doce River mouth, Espírito Santo State, Southeastern Brazil. Palaeogeography, Palaeoclimatology, Palaeoecology, 415: 48-58.

Costas S., Fitzgerald D. 2011. Sedimentary architecture of a spit-end (Salisbury Beach, Massachusetts): The imprints of sea-level rise and inlet dynamics. Marine Geology, 284: 203-216.

Davis Jr R., Clifton H.E. 1987. Sea-level change and the preservation potention of wave-dominated and tide-dominated coastal sequences. In: Nummedal D., Pilkey O.H., Howard J.D (eds.) Sea-level fluctuation and coastal evolution. Special Publication of the Society of Economic Paleontologists and Mineralogists, $156-177 \mathrm{p}$.

Dias G.T.M. 1981. O complexo deltaico do Rio Paraíba do Sul (Rio de Janeiro). In: Suguio K., De Meis M.R.M., Tessler M.G. (Eds.) Atlas IV Simpósio do Quaternário no Brasil, Publicação Especial -2 (CTCQ/SBG), Rio de Janeiro, 58-88p.

Dias G.T.M., Kjerfve B. 2009. Barrier and Beach Ridge Systems of Rio de Janeiro Coast. In: Dillenburg S., Hesp P. (eds.). Geology and Geomorphology of Holocene Coastal Barriers. Heidelberg: Springer Verlag, 225-248p.
Dillenburg S.R., Barboza E.G., Hesp P.A., Rosa M.L.C.C. 2011 Ground Penetrating Radar (GPR) and Standard Penetration Test (SPT) records of a regressive barrier in southern Brazil. Journal of Coastal Research, SI 64: 651-655.

Dillenburg, S.R., Barboza, E.G., Hesp, P.A., Rosa, M.L.C.C., Angulo, R.J., Souza, M.C., Giannini, P.C.F., Sawakuchi, A.O. 2014.Discussion: "Evidence for a transgressive barrier within aregressive strandplain system: implications for complexresponse to environmental change" by Heinet al. (2013), Sedimentology 60, 469-502A transgressive barrier at Pinheira, Southern Brazil around3 ka?. Sedimentology, 61: 2205-2212.

Dominguez J.M.L., Martin L., Bittencourt A.C.S.P. 1981. Esquema evolutivo da sedimentação Quaternaria nas feições deltaicas dos rios São Francisco (SE/AL), Jequitinhonha (BA), doce (ES) e Paraíba do Sul (RJ). Revista Brasileira de Geociências, 11(4): 227-237.

Dominguez J.M.L., Martin L., Bittencourt A.C.S.P. 1987. Sea-level history and Quaternary evolution of river mouth-associated beach-ridge plains along the east-southeast Brazilian coast: a summary. In: Nummedal, D.; Pilkey, O.H., Howard, J.D (eds.) Sea-level fluctuation and coastal evolution. Special Publication of the Society of Economic Paleontologists and Mineralogists, $115-127 \mathrm{p}$.

Elliott T. 1978. Clastic shorelines. In: Heading H.T. (ed.) Sedimentary environments and facies. Elsevier, New York, 143$177 \mathrm{p}$.

Engels S., Roberts M.C. 2005. The architecture of prograding sandygravel beach ridges formed during the last Holocene highstand: Southwestern British Columbia, Canada. Journal of Sedimentary Research, 75: 1052-1064.

Fernandez G.B., Rocha T.B. 2015. Barreiras Costeiras Holocênicas: Geomorfologia e Arquitetura Deposicional no Litoral do Rio de Janeiro. Revista Brasileira de Geomorfologia, 16(2): 301-319.

Fitzgerald D.M., Buynevich I.V., Rosen P.S. 2000. Geological Evidence of Former Tidal Inlets along a Retrograding Barrier: Duxbury Beach, Massachusetts, USA. Journal of Coastal Research, SI (34): 437-448.

Fracalossi F.G., Barboza E.G., Rosa M.L.C.C., Silva A.B. 2010. O registro em subsuperfície da barreira pleistocênica entre Osório e Tramandaí (RS). GRAVEL, 8(1): 21-31.

Fruergaard M., Moller I., Johannessen P.N., Nielsen L.H., Andersen T.J., Nielsen L., Sander L., Morten P. 2015. Stratigraphy, evolution and controls of a Holocene transgressive-regressive barrier island under changing sea level: Danish North Sea Coast. Journal of Sedimentary Research, 85: 820-844.

Hesp P.A., Dillenburg S.R., Barboza E.G., Tomazelli L.J., AyupZouain R.N., Esteves L.S., Gruber N.S., Toldo-Jr E.E., Tabajara L.L.C., Clerot L.C.P. 2005. Beach ridges, foredunes or transgressive dunefields? Definitions and an examination of the Torres to Tramandaí barrier system, Southern Brazil. Anais da Academia Brasileira de Ciências, 77 (3): 493-508.

Holz M. 2012. Estratigrafia de sequências: histórico, princípios e aplicações. Ed. Interciência, Rio de Janeiro, 258 p.

Komar P.D. 1998. Beach Processes and Sedimentation, 2nd edition Prentice Hall, New Jersey. 544 pp.

Kraft J.C., John C.J. 1979. Lateral and vertical facies relations of transgressive barrier. American Association of Petroleum Geologists Bulletin, 63: 2145-2163.

Lamego A.R. 1955. Geologia das Quadrículas de Campos, São Tomé, Lagoa Feia e Xexé. Divisão de Geologia e Mineralogia. Boletim n ${ }^{\circ}$ 154, DNPM, Rio de Janeiro.

Lessa G.C., Angulo R.J., Giannini P.C., Araújo A.D. 2000. Stratigraphy and Holocene evolution of a regressive barrier inouth Brazil. Marine Geology, 165: 87-108.

Machado G.M.V. 2007. Análise morfo-sedimentar da praia, antepraia e plataforma continental interna da linha de costa do Parque Nacional de Jurubatiba- RJ. Dissertação de mestrado. Programa de Pós-Graduação em Geografia, Departamento de Geografia Universidade Federal do Rio de Janeiro, 177p.

Maio C.V., Gontz A.M., Richard M. Ullivan R.M., Madsen S.M., Weidman C.R., Donnelly J.P. 2016. Subsurface Evidence of Storm-Driven Breaching along a Transgressing Barrier System, Cape Cod, U.S.A. Journal of Coastal Research, 32 (2): 264-279.

Martin L., Suguio K., Dominguez J.M.L., Flexor J.M. 1997. Geologia do Quaternário costeiro do litoral norte do Rio de 
janeiro e do Espírito Santo. CPRM Serviço Geológico do Brasil, $112 p$.

Martin L., Suguio K., Flexor J.M., Dominguez J.M.L. 1984. Evolução da planície costeira do rio Paraíba do Sul (RJ) durante o quaternário: influência das flutuações do nível do mar. Anais do Congresso Brasileiro De Geologia 33, Rio de Janeiro, p. 8497.

Muehe D., Fernandez G.B., Savi D.C. 2001. Resposta morfodinâmica de um sistema praia-antepraia à Oeste do Cabo Frio exposto à tempestade de maio de 2001. Boletim de resumos: mudanças globais e o Quaternário. VIII Congresso da ABEQUA, Imbé (RS), 63-64p.

Neal A. 2004. Ground-penetrating radar and its use in sedimentology: principles, problems and progress. Earth-Science Reviews, 66: 261-330.

Niedoroda A.W., Swift D.J.P., Hopkins T.S. 1985. The Shoreface. In: Davis R.A. (ed.). Coastal Sedimentary Environments. Springer-Verlag, 533-624p.

Nott J., Chague-Goff C., Goff J., Sloss C.; Riggs N. 2013. Anatomy of sand beach ridges: Evidence from severe Tropical Cyclone Yasi and its predecessors, northeast Queensland, Australia. Journal of Geophysical Research: Earth Surface, 118:1710-1719.

Otvos E.G. 2012. Coastal barriers - Nomenclature, processes and classification issues. Geomorphology, 139-140: 39-52.

Posamentier H.W., Jervey M.T., Vail P.R. 1988. Eustatic controls on clastic deposition I - conceptual framework. In: Wilgus B.S., Kendall C.G.St.C, Posamentier H.W., Ross C.A., Wagoner V. (eds). Sea level changes: an integrated approach. Society of Economic Paleontologists and Mineralogists Special Publication 42:109-124.

Psuty N.P. 1965. Beach-ridge development in Tabasco, México. Annals Assoc. Amer. Geog., n. 55, p.112-124.

Rocha T.B. 2013. A planície costeira meridional do complexo deltáico do rio Paraíba do Sul (RJ): arquitetura deposicional e evolução da paisagem durante o Quaternário Tardio. Tese de Doutorado. Programa de Pós-Graduação em Geografia, Departamento de Geografia, Universidade Federal do Rio de Janeiro, 178p.

Rocha T.B., Fernandez G.B. 2015. Registros geomorfológicos do Estágio Isotópico Marinho (MIS) 5a: evidências no Complexo Deltaico do rio Paraíba do Sul (RJ). Anais do XV Congresso da ABEQUA, Imbé (RS).

Rocha T.B, Fernandez G.B., Peixoto M.N.O, Rodriguez A. 2013a. Arquitetura deposicional e datação absoluta das cristas de praia pleistocênicas no complexo deltaico do Paraíba do Sul (RJ). Brazilian Journal of Geology, 43(4): 711-724.

Rocha T.B., Fernandez G.B., Peixoto M.N.O. 2013b Applications of ground-penetrating radar to investigate the Quaternary evolution of the south part of the Paraiba do Sul river delta (Rio de Janeiro, Brazil). Journal of Coastal Research, SI.65: 570-575.

Rocha T.B., Fernandez G.B. (em prep.) Geocronologia e radarfácies das cristas de praia do delta do rio Paraíba do Sul (RJ).

Rodriguez A.B., Meyer C.T. 2006. Sea-level variation during the Holocene deduced from the morphologic and stratigraphic evolution of Morgan Peninsula, Alabama, U.S.A. Journal of Sedimentary Research, 76: 257-269.

Roy P.S., Cowell P.J., Ferland M.A., Thom B.G. 1994. Wavedominated coasts. In: Carter R.W.G., Woodroffe C.D. (eds.). Coastal evolution: late quaternary morphodynamics. Cambridge University Press, 121-186p.

Santos R.A. 2006. Processos de Erosão e Progradação entre as praias de Atafona e Grussaí - RJ. Monografia de Graduação. Departamento de Geografia, Universidade Federal Fluminense, 36p.

Silva C.G. 1987. Estudo da evolução geológica e geomorfológica da região da Lagoa Feia, RJ. Dissertação de Mestrado. Programa de Pós-Graduação em Geologia, Departamento de Geologia, Universidade Federal do Rio de Janeiro, 116p.

Silva A.B., Barboza E.G., Rosa M.L.C.C., Dillenburg S.R. 2014. Meandering fluvial system influencing the evolution of a Holocene regressive barrier in southern Brasil. Journal of Coastal Research, SI 70: 205-210

Silva A.B., Barboza E.G., Rosa M.L.C.C., Fracalossi F.G. 2010. Caracterização dos depósitos sedimentares em subsuperfície no setor meridional da planície costeira sul de Santa Catarina. GRAVEL,8(1): 1-7.
Souza M.H.S. 1988. Clima de ondas ao norte do estado do Rio de Janeiro. Dissertação de mestrado. COPPE - Universidade Federal do Rio de Janeiro, Rio de Janeiro,181 p.

Souza M.C., Angulo R.J., Assine M.L., Castro D.L. 2012. Sequences of fácies at Holocene storm-dominated regressive barrier at Praia do Leste, Southern Brazil. Marine Geology, 291-294: 49-62.

Tamura T. 2012. Beach ridges and prograded beach deposits as palaeoenvironment records. Earth-Science Reviews,114: 279297.

Tamura T., Murakami F., Nanayama F., Watanabe W., Saito Y. 2008. Ground-penetrating radar profiles of Holocene raisedbeach deposits in the Kujukuri strand plain, Pacific coast of eastern Japan. Marine Geology, 248:11-27.

Tomaz E.A. 2005. Mapeamento de paleocanais ao longo da planície costeira do rio Paraíba do Sul e plataforma continental da bacia de campos e sua possível relação com a evolução do canyon Almirante Câmara. Dissertação de Mestrado. Programa de PósGraduação em Geologia, Departamento de Geologia, Universidade Federal do Rio de Janeiro, 108p.

Recebido 27 de janeiro de 2016 Aceito 21 de julho de 2017 